\title{
RELACIONES DIPLOMÁTICAS EN LA LITERATURA MEDIEVAL CASTELLANA
}

Entre los aspectos de la vida y la cultura españolas de la Edad Media, se destacan por su interés las noticias relativas a los contactos políticos de los cristianos con sus vecinos musulmanes. En la literatura castellana estas noticias se encuentran sobre todo en un género, el de las crónicas, a las cuales podemos añadir unos cuantos episodios de cantares épicos. Antes de considerar estas relaciones diplomáticas, conviene apuntar el interés que mostraron los historiadores de Castilla por los asuntos internos de los reinos musulmanes. La mayoría de las obras históricas, desde la Primera crónica de Alfonso X hasta la de los Reyes Católicos escrita por Diego de Valera, incluyen expresamente un resumen de los sucesos moros coetáneos a los acontecimientos cristianos que narran'. Tal interés por la historia musulmana se revela en la actitud de la Primera crónica: "Ca esta nuestra estoria de las Espannas general la leuamos nós de todos los reyes dellas et de todos los sus fechos que acaescieron en el tiempo passado, et de los que acaescen en el tiempo present en que agora somos, tan bien de moros como de cristianos..." ${ }_{2}$

Los cristianos tenían motivos para interesarse en los asuntos internos de los moros. Éstos, después de todo, representaban siempre el peligro más persistente que acechaba a los reinos del Norte; el conocimiento de su historia y de sus negocios les era indispensable para sus proyectos, tanto militares como diplomáticos. Aprovechando las disensiones intestinas de los moros, los cristianos podían escoger momentos oportunos para adelantar la Reconquista. Así, en tiempos de Fernando III la sublevación de Abenhut de Murcia contra los almohades les importaba a los cristianos porque, como resultado de la rebelión, "partióse aquella tierra en muchos pequennos reys, et apartada de los moros almohades, que fue pro et bien a lo que los cristianos teníen en los coraçones: esto es, ganar dellos la tierra"

${ }^{1}$ Las obras más importantes que manifiestan interés por los asuntos de los moros, por sus guerras dinásticas y por sus disensiones intestinas son la Primera crónica general de Alfonso X, la Crónica de Juan II, la Crónica del halconero, los Hechos de... Miguel Lucas de Iranzo y la Crónica de los Reyes Católicos de Diego de Valera.

\& Alfonso X, Primera crónica general, ed. R. Menéndez Pidal, NBAE, t. 5 , Madrid, 19o6, p. $6_{53} a$ (en adelante abreviaremos $P C G$ ). 
(PCG, p. 722a). Durante el reinado de Juan II, la lucha por el poder entre el rey Izquierdo y el rey Chiquillo motivó nuevas campañas contra Granada, y el monarca castellano pensó sacar partido de la discordia que había estallado dentro del reino andaluz ${ }^{3}$. Los historiadores regios reflejan la actitud de sus señores al tratar los asuntos de los moros. Las contiendas internas de éstos tenían que influir en la política cristiana, y era preciso incluirlas para mostrar completamente la historia de cada uno de los reinos.

En cuanto a las relaciones diplomáticas mismas, lo primero que importa considerar son los tratados y alianzas que se concertaron con los moros. Aunque no podía existir un plan duradero y bien detallado para la Reconquista, siempre se mantenía vivo el deseo de recobrar la tierra de manos de los moros y de expulsarlos finalmente de la Península. Claro que el método de hacerlo tenía que evolucionar según lo mandaban las circunstancias. Por eso la diplomacia podía ser tan buena arma como la guerra. En las negociaciones diplomáticas que vamos a considerar, podrá verse claramente la actitud práctica de los castellanos medievales para con los infieles.

La forma más elemental de convenio con los moros fue la tregua militar. A veces, claro está, la acción guerrera se suspendía simplemente sin acuerdo alguno entre los combatientes. Otras veces se concertaban treguas formales, por lo general para un período corto, un año o dos a lo más, aunque el plazo podía ampliarse si así parecía conveniente. Los cristianos conseguían con estas treguas varios fines: ganar tiempo para preparar la siguiente campaña, gozar de una pausa para que el rey pudiese afianzar su autoridad dentro del reino, o neutralizar a los moros mientras se emprendía una campaña contra otro estado cristiano. Alfonso VIII firmó una tregua con los moros dos años después de su derrota en Alarcos a fin de tener las manos libres contra León y Navarra (PCG, p. 682b). Alfonso XI ratificó una suspensión de hostilidades con el rey de Granada porque necesitaba tiempo para arreglar ciertas diferencias con su vasallo don Juan, hijo del infante don Manuel. Don Juan mismo mantenía relaciones amistosas con los moros, sin duda para apoyar mejor sus negociaciones con el monarca. Los musulmanes, por su parte, solían necesitar un respiro para ir a buscar ayuda en África. En una ocasión pidieron tregua y consintieron en pagar un tributo de doce mil doblas anuales ${ }^{4}$, pero lo cierto es que también el rey castellano anhelaba un período de paz. Varios otros tratados con los moros, siempre de corta duración y causados por análogos apremios, fueron concertados por Alfonso XI. Treguas como ésas eran bastante comunes, y se mencionan en las crónicas de casi todos los reyes castellanos de

${ }^{3}$ Crónica del halconero de Juan II, Pedro Carrillo de Huete, ed. J. de M. Carriazo, Madrid, 1946, p. 91; véase también la Crónica de Juan $I I, B A A E E$, t. 68 , pp. 483 ss.

${ }^{4}$ Crónica de Alfonso XI, BAAEE, t. 66, pp. 227-232. 
los dos últimos siglos de la Reconquista ${ }^{5}$. En muchos casos los moros tenían que pagar tributo o libertar a cierto número de cautivos cristianos.

Pero la paz no era siempre lo deseable. Cuando los cristianos se sentían bastante fuertes podían rechazar una petición de tregua o, si no, exigir una indemnización tan alta, que los moros no pudieran pagarla. Así, cuando Juan II quería hacer guerra contra el rey Izquierdo de Granada, desechó una oferta de paz, exigiendo que el moro le entregara "gran número de doblas e otras cosas, e que le diese todos los christianos que en su reyno estaban captivos, e que le otorgaría treguas por un año a lo más" (Crón. Juan II, p. $4^{84}$ a.) El rey castellano sabía que el moro no podría aceptar sus condiciones.

Alguna vez los acuerdos duraron tanto tiempo, que se los puede considerar como verdaderos tratados de amistad. Ejemplo conocido es el pacto de Alfonso VI con el rey de Toledo. Alfonso, huyendo de su hermano Sancho, se dirigió a la capital de Al-Ma'mun ibn Di'nNun, quien lo recibió con toda cordialidad ${ }^{6}$. Además de ayudar a su bienhechor contra el rey de Córdoba, Alfonso juró solemnemente que nunca atacaría ni a Al-Ma'mun ni a su hijo heredero. Cuando llegó al poder en Castilla y León, "seyendo él bueno et uerdadero, nunqua se le oluidó la postura que fiziera con Almemón rey de Toledo et con su fijo, et siempre los ayudó mientre uisquieron en las cosas que ouieron mester" (PCG, p. $520 b$ ). El pacto sólo se refería a Al-Ma'mun y a su hijo Yssem, de manera que no fue obstáculo para que Alfonso tomase más tarde a Toledo, cuando Yssem ya no mandaba allí. Tal era el esquema general de las relaciones diplomáticas en la Edad Media española. Los tratados se concertaban entre individuos. Si uno de los contratantes moría, o si era destronado, como a menudo ocurría entre los moros, el acuerdo quedaba abrogado. Así, pues, los pactos con los moros jamás tuvieron un carácter muy permanente.

De índole distinta fue el tratado que firmaron Juan II y el rey de Túnez. Éste, aunque moro, prometió no ayudar a Granada contra Castilla (Crón. Juan II, p. 488a; véase también Crón. halconero, p. 127). A los cristianos les convenían acuerdos de esta clase para neutralizar cualquier ayuda que buscasen sus enemigos. Representaban un aspecto de la política de "dividir para vencer", de la que pronto veremos ejemplos más notables.

5 Algunos ejemplos de las muchas treguas que se firmaron pueden verse en Fernán SÁnchez de Valladolid, Crónica de Sancho el Bravo, BAAEE, t. 66, pp. 72a, 84b-85a, y Crónica de Fernando $I V$, ibid., p. $133^{a}$; Pero López DE Axala, Crónica de Juan $1, B A A E E$, t. 68, p. 142b, y Crónica de Enrique $I I I$, ibid., p. 224a; Crónica de Juan II, ibid., p. $333^{b}$.

- La residencia de Alfonso en Toledo se relaciona con la historia del cerco de Zamora y con la materia cidiana. 
Los tratados que hasta aquí hemos examinado son de carácter esencialmente negativo. Es decir, representan acuerdos según los cuales los cristianos y los moros prometen no atacarse mutuamente durante cierto tiempo, o bien se obligan a no ayudar a los enemigos del otro bando. De índole más positiva son las alianzas en que se establece un intercambio de ayuda militar. En ciertos casos un rey cristiano aceptó auxilio de los moros contra otros cristianos. Sancho I de León recobró su reino de manos de Ordoño el Malo con ayuda de un ejército que le dio Almanzor, según la Primera crónica. De modo semejante ayudaron los moros al conde García de Navarra en sus luchas contra Pedro de Aragón y Fernando el Magno de Castilla (PCG, pp. 4oga, 476a, 484b). Pedro el Cruel obtuvo auxilio de Granada tanto para sus guerras exteriores como para reprimir los desórdenes ocurridos dentro del reino. Cuando don Pedro guerreaba contra Aragón, el rey Mahomad de Granada le proporcionó tres galeras, y mandó a un caballero, don Farax Rodoán, con seiscientos jinetes para ayudar a los castellanos. López de Ayala también sostiene que el rey cristiano fue amparado por mil quinientos jinetes moros en la batalla de Montiel, donde murió a manos de su hermanastro Enrique de Trastámara. A cambio de la ayuda recibida, don Pedro había apoyado a Mahomad contra su rival, el llamado rey Bermejo. Según Ayala, el rey Bermejo acudió a don Pedro pidiéndole que juzgase el pleito suyo con Mahomad, pero el castellano, que codiciaba las joyas del moro, le hizo prender y matar, junto con sus secuaces, "e el rey Bermejo, desque se vio ferido, dixo al rey en su arábigo: «OH, qué pequeña caballería feciste!»... E decía el rey don Pedro que él los ficiera matar porque se alzaran e fueran rebeldes a su señor el rey Mahomad, e porque fueran en matar al rey Ismael su señor; empero todos lo tovieron por non bien fecho, e les ploguiera que el rey non lo ficiera así" 7 .

Más frecuentes fueron las alianzas en virtud de las cuales un rey de Castilla ayudó a uno de los reyezuelos moros contra otros. $\mathrm{Mu}$ chas veces se trataba de favorecer a un aspirante al trono de Granada contra sus rivales. Ya hemos mencionado las amistades de $\mathrm{Al}$ fonso VI y Al-Ma'mun y de Pedro I y Mahomad. Alfonso X y el rey de Granada se juntaron para guerrear contra Murcia, pensando cada uno extender sus propios dominios. Poco después, Alfonso se alió con otros moros, los arrayaces, contra el rey de Granada, quien a su vez recibió el sostén de los ricos-hombres castellanos que estaban enemistados con Alfonso ${ }^{8}$. Juan II, después de la muerte del rey Chiquillo, apoyó las pretensiones de Abenalmao al trono de Granada y le ayudó a ganar un poder transitorio en la capital anda-

\footnotetext{
" Pero López de Ayala, Crónica del rey don Pedro, BAAEE, t. 66, pp. $494 b, 526 b, 589 b, 519 a b$.

s Fernán Sánchez de Valladolid, Crónica de Alfonso X, BAAEE, t. 66, 1 $b$ y $34 a$.
} 
luza. Después de su victoria en la Vega de Granada el ${ }^{9}$ a de julio de 1431, don Juan le mandó a Abenalmao "que dende en adelante él se llamase rrey de Granada" (Crón. halconero, pp. 104-106). Aunque don Juan se mostró amistoso con Abenalmao, su apoyo no se debió completamente a amistad. Fue método eficaz de mantener vivos los trastornos internos en Al-Andalus. La explicación principal de la buena fortuna de los castellanos está en el hecho de que los musulmanes nunca pusieron fin a sus luchas intestinas ni ofrecieron un frente unido a los cristianos. Hasta los últimos momentos de la Reconquista, la campaña castellana debió muchos de sus triunfos a los conflictos existentes en Granada y a la defección del rey Mozo en favor de los Reyes Católicos. Todavía en 1487, algunos moros de la facción del joven rey servían a Fernando contra el rey Viejo. Mediante la promesa de tres años de paz al rey Mozo, Fernando logró mantenerlo alejado de su tío ${ }^{9}$. Sin embargo, aunque una reconciliación entre los dos reyezuelos hubiera podido prolongar la lucha, en realidad no habría cambiado el resultado inevitable.

Salta a la vista que las consideraciones religiosas tenían poco que ver con las relaciones diplomáticas. Las diferencias de credo rara vez hicieron que los castellanos se negaran a firmar pactos de ayuda mutua con los moros, a militar en sus filas o a aceptar su ayuda. Puede ser que alguna vez tales alianzas les pareciesen poco apetecibles, pero los españoles cristianos se mostraron sumamente realistas en sus tratos con la gente que compartía con ellos el territorio de la Península. Aun en los casos en que rehusaban la ayuda militar ofrecida por los musulmanes, lo hacían cortésmente para no contrariarlos y para asegurar su ayuda si les hacía falta en lo futuro ${ }^{10}$. La práctica de apoyar a un moro contra otro muestra igualmente su actitud realista, aunque no se puede negar que ésta fue una política extranjera bastante precaria, no sólo por las fluctuaciones de poder entre los moros, sino también por la falta de estabilidad en Castilla misma, sobre todo en los siglos xiv y xv. Cuando había alborotos internos, resultaba difícil conservar los triunfos que se ganaban interviniendo en los asuntos internos de Granada ${ }^{11}$. Castilla no gozó

- Diego de Valera, Crónica de los Reyes Católicos, ed. J. de M. Carriazo, Madrid, 1927, pp. 217 ss.

${ }^{10}$ La Crónica de Juan II cuenta (p. 668b) con qué tacto procedió el rey Juan de Navarra cuando los moros le ofrecieron ayuda contra Castilla: les dio una respuesta dilatoria, "hasta ver si hallaba en los caballeros de Castilla tanto favor, que pudiese escusar el favor del rey de Granada y de los moros, e donde no lo pudiese hallar en tanto grado como cumplía a él y a los caballeros de su opinión, que entonces no podría escusar el favor del rey de Granada por recobrar lo que sin causa perdido había".

${ }^{11}$ Por ejemplo, muchos de los pueblos que Juan II había ganado en sus campañas en apoyo de Abenalmao se perdieron más tarde cuando los moros, a su vez, se aprovecharon de las disensiones suscitadas alrededor de don Álvaro de Luna para atacar a Castilla (Crón. halconero, pp. 487 s., 532 s.). 
de bastante armonía interna para consolidar sus victorias hasta fines del siglo xv. Pero el hecho de que los reyes castellanos anteriores a Fernando e Isabel no hayan podido realizar un programa sostenido no quiere decir que su actitud fuese poco práctica. El apoyo que prestaron a ciertos moros contribuyó a mantener el estado de desunión en Andalucía y permitió que los castellanos ganasen nuevas tierras sin gasto excesivo de vidas ni de dinero. Si triunfaba el moro a quien sostenían, recibía su tributo y, por lo común, contaba con su vasallaje y amistad. Si perdía, su contrincante quedaba debilitado por la lucha y no podía atacar a los cristianos.

Pero no eran sólo los reyes de Castilla quienes solían pactar alianzas con los moros. Refiriéndose al Cid, Menéndez Pelayo dice que "las alianzas con infieles y el militar a sueldo suyo, aun contra príncipes cristianos, eran corrientes en el derecho público de la época, y privilegio inconcuso de los ricos-hombres, según se desprende de la lectura del Fuero Viejo de Castilla" 12. El derecho de los nobles castellanos a pactar con los moros se prolongó hasta el siglo xv. Los primeros ejemplos literarios de alianzas de individuos particulares con los infieles se hallan en los cantares épicos. Bernardo del Carpio, según la tradición peninsular, se alió con el rey de Zaragoza, el Marsil de los autores medievales castellanos, para conseguir una victoria nacional sobre los franceses en Roncesvalles ${ }^{\mathbf{1 3}}$. Se admite que esta leyenda de cooperación moro-cristiana surgió como protesta contra las pretensiones francesas de victorias logradas en la Península. Rodrigo Díaz de Vivar se alió con los reyes de Zaragoza al principio de su destierro, y aun antes de esto había ayudado al rey de Sevilla (vasallo de Alfonso VI) contra el rey de Granada y contra los cristianos que apoyaban a éste. El Poema del Cid no menciona sus alianzas con estos moros, pero la Primera crónica nos lo dice con bastantes pormenores. Debido a las hazañas que llevó a cabo mientras servía a Almutamiz de Sevilla contra Almudafar de Granada, Ruy Díaz ganó el título de "Cid Campeador" (PCG, p. 522b). Durante su destierro, el Cid ayudó a Zulema, rey de Zaragoza, contra Abenalhage de Denia, cuyas tierras eran defendidas por otros cristianos, Pedro de Aragón y el conde Ramón Berenguer; "et Çulema rey de Saragoça amó mucho a Roy Díaz, et diol todo su regno en poder et en guarda, et mandó a sus uassallos que fiziessen todo lo que él mandasse" (ibid., p. 532b). En su campaña contra Valencia, Ruy Díaz trató con varios cabecillas moros $y$, aunque nominalmente seguía siendo vasallo de Alfonso VI, en realidad actuaba como señor independiente. Tenía derecho de ha-

12. M. Menéndez Pelayo, Antologia de poetas liricos castellanos, Madrid, $1890-1906$, t. 11, p. 301 .

${ }^{13}$ Véanse el Poema de Fernán González, estr. 140-143, y la PCG, p. 353a; y cf. R. Menéndez Pidal, "Notas para el romancero del conde Fernán González", Homenaje a Menéndez Pelayo, Madrid,' 1899, p. 448. 
cerlo, según el código feudal. No obstante, en sus alianzas con los moros parece que el Cid tuvo cuidado de no ponerse en pugna abierta con su soberano.

Tal escrúpulo no caracterizó a los ricos-hombres que se aliaron con los infieles en épocas posteriores. En efecto, a juzgar por las crónicas, la razón de más peso que tenían los nobles para pactar con los moros era oponerse al poder real. En el reinado de Alfonso $\mathrm{X}$, el infante don Felipe, hermano del rey, salió con los suyos de Castilla en rebelión abierta contra Alfonso y se dirigió a Granada, donde firmó con el rey moro un tratado de mutua ayuda. Los rebeldes pasaron dos años en Granada y no volvieron hasta que se celebró una reconciliación con el rey gracias a la mediación de la reina (Crón. Alfonso X, pp. 23 ss., 32 ss., 46b). Los hijos de Alfonso también riñeron, y Juan, hermano de Sancho IV, se fue a Marruecos y peleó al lado de los musulmanes (Crón. Sancho el Bravo, p. 8ga). Volvió a Castilla después de la muerte de Sancho, pero inmediatamente regresó a tierra de moros. Junto con el rey de Granada guerreó contra su sobrino Fernando IV y la regente doña María (Crón. Fernando $I V$, p. $102 b$ ). Murió en Granada en los primeros años del reinado de Alfonso XI. Otro don Juan, el hijo del infante don Manuel, se alió con los moros varias veces contra el vencedor del Salado (Crón. Alfonso XI, pp. 209b-210a y 233ab). Los nobles que se opusieron a Pedro el Cruel quisieron ganarse la ayuda de los moros en su lucha contra el monarca. Don Juan de la Cerda fue a Granada y luego a Africa para solicitar alianzas con los mahometanos (Crón. D. Pedro, p. 426a). Pero los de Granada se encontraban divididos a la sazón y ambas parcialidades competían por el favor de don Pedro. Así, pues, el emisario no tuvo ningún éxito. Como ya queda dicho, don Pedro optó por su vasallo Mahomad e hizo matar al rival.

Alianzas parecidas encontramos en el siglo xv, durante los reinados de Juan II y de Enrique IV. En las dificultades que el primero de estos monarcas tuvo con sus propios nobles, con los navarros y con los aragoneses, los moros proporcionaron gente de guerra a los enemigos del rey. Gómez Manrique y sus hermanos Rodrigo y Fadrique, así como sus parientes de la poderosa familia Mendoza, emplearon a soldados sarracenos contra las fuerzas reales (Crón. halconero, pp. 494 s., 497 s., 514, 534). En tiempos de Enrique IV, los ricos-hombres solían reclutar mercenarios moros para sus contiendas particulares. Alfonso Fajardo, adelantado de Murcia, “como estaba poderoso, hacía muchos males, unas veces metiendo moros que robaban la tierra e captivaban los christianos, e otras guerreando e disipando muchos lugares"14. El biógrafo de Miguel Lucas de Iranzo y Fernando del

${ }^{14}$ Diego Enríquez del Castillo, Crónica de Enrique IV, BAAEE, t. 7o, p. $110 b$. Menéndez Pelayo, Antologia, ed. cit., t. 8, pp. 164-165, identifica al 
Pulgar se refieren a las confederaciones que formaron con los moros el Conde de Cabra y sus enemigos para oponerse unos a otros ${ }^{15}$.

Las alianzas que los ricos-hombres hacían con los moros se parecen a los pactos concertados por los monarcas en que muestran la cooperación y las relaciones amistosas que cabían entre personas de religiones diferentes. En ninguno de esos casos se observa gran repugnancia en tratar con los enemigos tradicionales del cristianismo. Sin embargo, hay una distinción importantísima entre los acuerdos firmados por el soberano y los que hacían los nobles. Los primeros podían contribuir a la hegemonía y unificación de Castilla, ya sea reforzando la posición del rey dentro de sus tierras, ya aumentando la desunión entre los moros. Los segundos tenían un efecto totalmente opuesto. Como los nobles se aliaban con los moros las más veces para oponerse a su propio señor, sus acciones estorbaban la unidad castellana. Fue esto lo que ocurrió sobre todo en los dos últimos siglos de la Reconquista, cuando el poder de los nobles rivalizaba a menudo con el del rey. Varios cronistas del siglo xv se hicieron cargo de lo peligrosa que era tal actividad diplomática por parte de individuos particulares. Enríquez del Castillo desaprueba abiertamente el hecho de que Alonso Fajardo se sirva de los moros en esa forma, y los autores que mencionan el caso del Conde de Cabra y sus enemigos se indignan asimismo de sus tratos amistosos con los musulmanes. Pero estas protestas son las únicas que hemos hallado en los escritos castellanos de la época ${ }^{16}$. Los tratados con los moros fueron cosa común y corriente en la vida medieval, y demuestran que es errónea la idea de la Reconquista como un continuo batallar contra los enemigos de la fe. El ideal de la Reconquista se mantenía siempre vivo, pero en la práctica solían pesar más las consideraciones del momento.

Al estudiar las relaciones moro-cristianas hay que tener en cuenta el vasallaje prestado por una persona de una religión a un señor de otra. Desde luego, el vasallaje de cristianos a moros era más frecuente cuando éstos llevaban la ventaja. La Primera crónica menciona varios casos de cristianos que acudieron a militar bajo los morosi7,

Fajardo del romance "Jugando estaba el rey moro..." con este Alonso Fajardo, pero E. Buceta, en RFE, 18 (1931), 24-33, dice que se trata de Pedro Fajardo, primo de Alonso. En todo caso, el romance nos ofrece una prueba más de las relaciones amistosas que solía haber entre personas de distinta religión en la España del siglo xv.

${ }^{15}$ Hechos del condestable don Miguel Lucas de Iranzo, ed. J. de M. Carriazo, Madrid, 1940, pp. 463 y 467 ; Fernando del Pulgar, Letras..., ed. J. Domínguez Bordona, Clás. cast., Madrid, 1929, pp. 127-128.

${ }_{16}$ Menéndez Pelayo, op. cit., t. 11, p. 203, dice que el autor del Poema de Fernán González hace ciertas "salvedades" a la alianza de Bernardo del Carpio con el rey Marsil.

${ }^{17}$ Véanse algunos ejemplos en la $P C G$, PP. $345^{a}, 445^{a b}, 5^{\circ} 3^{b}, 684^{a}, 717^{b}$, $719 b, 731 b$. 
sobre todo en la época de poderosos caudillos como Abderramán I y Almanzor. Los territorios musulmanes ofrecían asilo cuando, por razones políticas o de otra índole, se le hacía imposible a alguien quedarse en Castilla. Así, Alfonso VI buscó refugio en la corte del rey de Toledo en 1072, cuando su hermano Sancho le usurpó el trono. La Crónica de Alfonso XI dice (p. 259a) que los hermanos Aguilar, don Gonzalo y don Fernán, se hicieron vasallos del rey de Granada. La misma crónica nos cuenta (p. 312b) que algunos cristianos que vivían entre los musulmanes del África septentrional tomaron parte en las revueltas dinásticas de allí: "Muerto Abotebid rey, los christianos que eran allén la mar alzaron rey [a] Aborrabe su hermano". Las tierras de moros también ofrecían asilo a esclavos fugitivos y a renegados. Las Siete partidas dieron cierto reconocimiento legal a esta costumbre, pues declaran que los esclavos que huyan a tierra de moros han de considerarse libres (IV, tít. 22, ley 7). Granada siguió siendo un refugio para esta gente hasta su caída en poder de los Reyes Católicos.

Puesto que nos servimos aquí de fuentes cristianas, es natural que el vasallaje de moros a cristianos se mencione mucho más a menudo que el de éstos a aquéllos. Casi todas las treguas de los tres últimos siglos de la Reconquista, por lo menos tal como las presentan los cronistas castellanos, incluyen el reconocimiento, por parte del caudillo moro, de su vasallaje al monarca castellano, y la promesa de pagarle tributo. Baste citar unos cuantos ejemplos. Fernando I recibió el homenaje de los reyes de Toledo y Sevilla, quienes le pagaron tributo, en el cual iba incluido el cuerpo de San Isidoro, entregado por Almutamid de Sevilla (PCG, pp. 489-49o). Alfonso VI recibió treinta mil maravedies anuales del hijo de cierto Abubécar a cambio de la protección que le ofreció (ibid., p. 552a). Abenganía de Córdoba fue vasallo de Alfonso VII (ibid., pp. $\left.655^{b-6} 5_{5} 6\right)^{18}$. Los reyezuelos de Baeza, Murcia y Granada rindieron homenaje al santo rey Fernando III. La acogida que éste dispensó al rey de Granada (ibid., p. $746 b$ ) revela su generosidad para con un vasallo musulmán:

Et el rey don Fernando, llenno de piadamiento et de toda mesura, veyendo en cómmo ese rey moro venía con grant humildat et tan paçiente a plazimiento de quanto él de la tierra et dél quisiese fazer, nol forçando cobdiçia maligna, la qual él nunca ouo, et guiándol mesuramiento et piadança natural..., reçibiól muy bien et fízol mucha onrra, et non quiso dél otra cosa saluo que fincase por su uasallo con toda su tierra, et se la touiese commo se la ante teníe con todo su sennorío, et quel diese della tributo

18 La Crónica dice que a Abenganía se le permitió jurar sobre el Corán, nuevo indicio de lo poco que influían las diferencias religiosas en asuntos polí ticos. 
çierto: cada anno çient et çinquenta mill morauedís, et le feziese della gerra et paz, et le veniese cada anno a cortes.

Esta moderación hacia el moro resulta más notable si se tiene en cuenta que el rey de Granada se hizo vasallo de Fernando sólo por necesidad, después de ser vencido en batalla y de perder la ciudad de Jaén. En cuanto al rey de Castilla, es posible que le haya ofrecido condiciones tan benignas para terminar esa fase de la guerra, puesto que también hacía campaña contra Sevilla y ansiaba tomarla. En todo caso, su política de suavidad dio buenos resultados: el rey de Granada se hizo su leal vasallo, le prestó ayuda militar y, en cambio, recibió su protección. Al morir Fernando, el musulmán "mandó fazer grandes llantos por todo su regno" (PCG, p. 774a). Además, mandó emisarios que asistieron a las exequias de don Fernando en el aniversario de su muerte ${ }^{19}$.

También Alfonso X recibió el vasallaje de Granada, aunque no disfrutó de él de manera continua, a causa de sus guerras y de sus disensiones con los nobles y con su hijo Sancho. Después de la guerra contra Murcia, llevada a cabo juntamente por Castilla y Granada, Alfonso estableció a cierto Mahomad como reyezuelo de la ciudad, "porque este rey don Alfonso avía voluntad de aver reyes por vasallos" (Crón. Alfonso X, p. 11 b). Los reyes posteriores tuvieron asimismo vasallos moros. Entre los súbditos de Alfonso XI hubo un Abrahén el Beodo, llamado así por su afición al vino, y en más de una ocasión el rey de Granada se declaró vasallo del castellano y le pagó tributo (Crón. Alfonso XI, pp. 204b, 228a; Poema de Alfonso XI, v. 2447). Como ya hemos recordado, Pedro I recibió el homenaje de Mahomad de Granada a cambio de su apoyo contra el rey Bermejo. Los cronistas no vuelven a mencionar vasallajes de moros hasta el reinado de Juan II. Al parecer, Enrique II, Juan I y Enrique III no pudieron imponer sujeción a sus vecinos del Sur. Jusaf Abenalmao, el malogrado pretendiente al trono de Granada, se declaró vasallo de Juan II y fue apoyado por él cuando quiso apoderarse de la ciudad. La Crónica del halconero (pp. 121-122) transcribe esta carta suya a don Juan:

Señor, el vuestro vasallo Juçab Venalmao, rrey de Granada, vesa vuestras manos e me encomiendo en vuestra merced... $\mathrm{E}$ agora, señor, con la graçia de Dios e con esfuerço de vuestra merced, el vuestro adelantado del Andaluzía don Diego Gomes de Ribera e mis caualleros van a Málaga, donde está el rrey Esquierdo, e fiança

18 "Aben-Alhamar, rey de Granada, enviaba al rey don Alfonso para esta honra, cuando la facían, grandes homes de su casa, e con ellos cient peones, que traía cada uno un cirio ardiendo de cera blanca. E estos cient cirios poníanlos aderredor de la sepoltura do yacía enterrado el rey don Ferrando, e esto facía Aben-Alhamar por honra del rey" (Crón. Alfonso X, p. 8a). 
tengo en Dios e en esfuerço de la vuestra merced que yo lo abré en las manos...20

El pobre Abenalmao murió en 1432, el mismo año en que llegó a ser rey. Más tarde Juan II ayudó al infante Izmael contra el infante Coxo, después de haber destronado éste a su tío Mahomad el Izquierdo (Crón. Juan II, p. 638a). A Enrique IV, cuya inclinación hacia los musulmanes es bien conocida, le rindieron homenaje Mahomad, hermano del rey de Granada, y Aliquezote, comandante de Málaga. Enríquez del Castillo dice que éste le dio al rey obsequios de caballos "e otras cosas moriscas, con que el rey ovo mucho plascer, teniéndoselo en servicio e agradesciéndoselo mucho" (Crón. Enrique IV, p. 186a). Y Mahomad se pasó al servicio de don Enrique con ochenta caballos porque temía por su vida a manos de su hermano ( $\mathrm{He}$ chos de... Iranzo, p. 20o). Hasta los Reyes Católicos aceptaron el vasallaje de Boabdil, el "rey Chico" de Granada, para fomentar la desunión entre los moros.

El vasallaje de los moros en favor de los monarcas castellanos se explica por varias razones. A menudo se les imponía como estipulación de un tratado de paz, y llevaba anejo un tributo anual. A veces los castellanos podían hacer que los moros les rindiesen homenaje a fuerza de su superioridad militar, pero para mantener su soberanía tenían que conservar esa superioridad. En cuanto los moros se sentían bastante fuertes, sacudían su dependencia y dejaban de pagar el tributo. Otras veces los moros se hacían vasallos voluntariamente. Tal fue el caso de los pretendientes al trono de Granada que deseaban ayuda cristiana para sus tentativas de insurrección. Finalmente, los reyes de Castilla procuraban obtener el vasallaje de los moros para mantenerlos divididos y, por consiguiente, debilitados.

Concluyamos con unas palabras sobre el intercambio de emisarios y la manera de tratar a los mensajeros de los moros. Es natural que hubiera este intercambio. Los muchos tratados de paz, treguas, ofertas de ayuda mutua y peticiones de auxilio exigían negociaciones diplomáticas de una u otra clase. Casi todas las crónicas mencionan la llegada de mensajeros de los infieles o el envío de representantes cristianos a sus tierras. No hay indicación alguna de que moros y cristianos tuvieran dificultades en comunicarse, ni siquiera en tiempos de guerra activa. Las Siete partidas enumeran incluso los derechos del mensajero diplomático de los $\operatorname{moros}^{21}$. El intercam-

${ }^{20}$ La Crónica de Juan $I I$ añade (p. $5^{\circ} 3^{b}$ ) que Abenalmao "se otorgó por vasallo del rey, puesto por su mano en aquel reyno, e se obligó a dar al rey e a la corona de sus reynos cierta quantía de millares de doblas en cada año en parias, e haber e cumplir otras ciertas cosas de vasallage".

21. Partida VII, tít. 25, ley 9: "Mensageros vienen a las vegadas de tierra de moros et de otras partes a la corte del rey; et maguer vengan de tierra de los enemigos por mandado dellos, tenemos por bien et mandamos que todo men- 
bio de embajadores fue sumamente frecuente en el siglo $\mathrm{xv}$, a juzgar por las menciones que de ello se encuentran en las crónicas de entonces. La Crónica del halconero cuenta (p. 127) que los embajadores del rey de Túnez ante la corte de Juan II fueron cristianos, y que los musulmanes los llamaban "farfanes". Los Hechos de Miguel Lucas de Iranzo, crónica que muestra mejor que ninguna otra la vida doméstica y las costumbres y festividades del siglo $\mathrm{xv}$, presentan (pp. 109-110) un cuadro gráfico de la recepción ofrecida a ciertos embajadores moros en una ciudad fronteriza. En una ocasión, tres o cuatro caballeros granadinos vinieron a negociar con el condestable. Acaeció que llegaron a Jaén tres días antes del miércoles de ceniza, y así las carnestolendas se celebraron en su honor. Entre las diversiones presentadas en esos tres días se contaron ejercicios ecuestres, momos, bailes y torneos. El objeto de estos últimos fue impresionar a los moros con las fuerzas que tenía Iranzo en Jaén, y el autor repite que los mensajeros quedaron "maravillados" y "espantados". El carnaval tuvo gran éxito: "Fue cosa por çierto que a todos bien paresçió, mayormente a los moros, que dicíen vnos a otros axudy". Este informe, aunque algo desdeñoso para los infieles, a quienes se atribuyen reacciones de susto y sorpresa ante lo que vieron, indica sin embargo la actitud que predominaba en la frontera. El pasaje se caracteriza por un tono ligero y natural, que da a entender que la llegada de emisarios musulmanes era acontecimiento que podía ocurrir en cualquier momento. La cordial acogida que éstos tuvieron y los festejos celebrados en su honor muestran que eran posibles relaciones personales amistosas entre individuos de diferentes religiones.

Los relatos históricos de todas estas actividades diplomáticas revelan el comportamiento civilizado de los castellanos medievales para con sus enemigos tradicionales. Los españoles de entonces se guiaron por principios de derecho internacional en sus tratos con ellos, firmaron tratados solemnes con los reyes musulmanes, canjearon con ellos embajadores y reconocieron derechos diplomáticos a sus emisarios. Además, el concepto feudal fue lo bastante flexible en España para incluir a menudo a los moros en la categoría de vasallos.

Ohio State University.

KenNeth R. Scholberg

sagero que venga a nuestra tierra, quier sea cristiano, o moro o judío, que venga et vaya salvo et seguro por todo nuestro señorí; et defendemos que ninguno non sea osado de facerle fuerza, nin tuerto nin mal ninguno a él nin a sus cosas. Otrosí decimos que, maguer el mensagero que viniese a nuestra tierra debiese alguna debda a home de nuestro señorío que fuese fecha ante que viniese en la mensageria, que nol prendan por ello nin le trayan a juicio; mas las debdas que ficiere en nuestra tierra después que viniese en la mensageria, si las non quisiese pagar, bien gelas pueden demandar, et apremiar por juicio que las pague". 